\title{
Study, Design and Implementation of a Supermarket Trolley with Minimal Motor-driven Physical Propulsion to Drive It
}

\author{
Kavetsos Dimitris \\ Dept. of Industrial Design and \\ Production Engineering, UNI.W.A \\ Athens, Greece
}

\author{
Drosos Christos, PhD \\ Dept. of Industrial Design and \\ Production Engineering, UNI.W.A \\ Athens, Greece
}

\author{
Piromalis Dimitris, $\mathrm{PhD}$ \\ Dept. of Industrial Design and \\ Production Engineering, UNI.W.A \\ Athens, Greece
}

\begin{abstract}
The rapid advances in technology in all areas have spurred the development of new innovative technological solutions simpler and safer - in order to improve the everyday life of the human being. In recent years, the mechatronics industry has presented a variety of applications in many areas of everyday life. In particular, in the field of modern retail, technological solutions have been developed so that consumers can obtain their products easily and quickly. With regard to supermarkets, automated consumer-related processes are still limited compared to other stores. The present work presents the design and construction of a supermarket cart with automation that requires minimal physical impulse to move it in order to facilitate and safer service to the consumers. In addition, the design of the system, its peripheral components, and the programming code developed to achieve the movement of the trolley are described. The conclusions of the study and the advantages of applying this trolley are summarized.
\end{abstract}

\section{Keywords}

Supermarket cart, automation, microcontroller, power cell, motor.

\section{INTRODUCTION}

Automation systems in recent years have contributed decisively to facilitating everyday human actions using modern technology. Taking into account the need to find easier ways of living, the research question in this paper is how the science of automation can contribute to the development of a system aimed at improving and facilitating the day-to-day life of man by developing and using a supermarket cart assisted by mechanical and minimal physical push.

The development of such a modern and safe supermarket trolley will greatly facilitate the consumer's everyday life, while passing through the supermarket will make safe and easy. The contribution of this trolley will be crucial for people who may experience some motor problems.

In addition, the development of this system contributes to science as it develops an innovative automation system that has not been implemented in Greece, while tricky automation steps for supermarket trolleys have been done abroad..

\section{STATE OF THE ART}

The automated trolley systems found in the international literature are mainly based on wireless communication between trolley, host and client, and most systems for their operation use the Arduino development board. Typically, the Harpreet Singh Bedi team in 2017, presented a smart supermarket cart that combines the use of a smartphone and the Arduino board. Through the Arduino board communication with the mobile phone and other accessories is achieved in order to obtain the desired product information from the consumer.

Sneha S. Naik and his colleagues developed a polymorphic shopping cart in the supermarket with a Wi-Fi charging system. Initially the barcode is scanned and the description and price of the prodact scanned trolley is displayed on the LCD display. The payment of the product from the customer's data via wireless communication (Wi-Fi) between the trolley and the supermarket host is then made. The proof of payment is printed, and the lid with the trolley opens and places the product inside it and then closes. This system features Arduino, which connects the LCD screen, the barcode scanner and the proof printer.[5]

OYen Leng $\mathrm{Ng}$ and his team have developed a scooter that has the ability to move automatically. In particular, this trolley moves on its own, without pushing, following the customer's purchases while providing the convenience of directing the customer to the shelf of the product that interests him. The trolley achieves these functions through a robotic system that is placed under the trolley. This system consists of an Arduinomega 2560, ultrasonic sensors to prevent a customerdriven collision accident, from line sensors through which the trolley perceives the lines in the supermarket and follows them in order not to lose its course and by electric motors to drive it. The RFID feature of the robotic system enables it to communicate via Arduino and the host with RFID products. Throughout this communication also contributes the client's mobile that communicates with the system.[4]

You-ChiunWang and Chang-ChenYang refer to the utilization of IoT and the wireless network (WirelessSensorNetwork (WSN)) to develop an intelligent supermarket trolley to provide customer service. The cartoon developed has pressure sensors to perceive the system (presumed salesman) of the trolley movement, ie whether the customer is moving on a particular runway or is stationary in the corridor looking for a particular product on the shelves of this corridor. In addition, by the consumer, via the screen mounted on the trolley.[7,8]

This study presents for the first time the development of a supermarket cart whose movement is influenced by the driving forces exerted on the trolley handle.

\section{SYSTEM DESIGN.}

Below is a flow chart depicting the operation of the automated trolley movement system (Figure 1). At first the consumer lightly presses the handle, selects the movement that the trolley will make, ie whether it moves backward (pulling) or 
moves forward (push). In addition, if the distance from a possible obstacle is more than $30 \mathrm{~cm}$, the distance sensor allows the trolley to move the green light and the motors are turned on, if not then the red indicator is activated and the trolley does not move and the motors are deactivated.

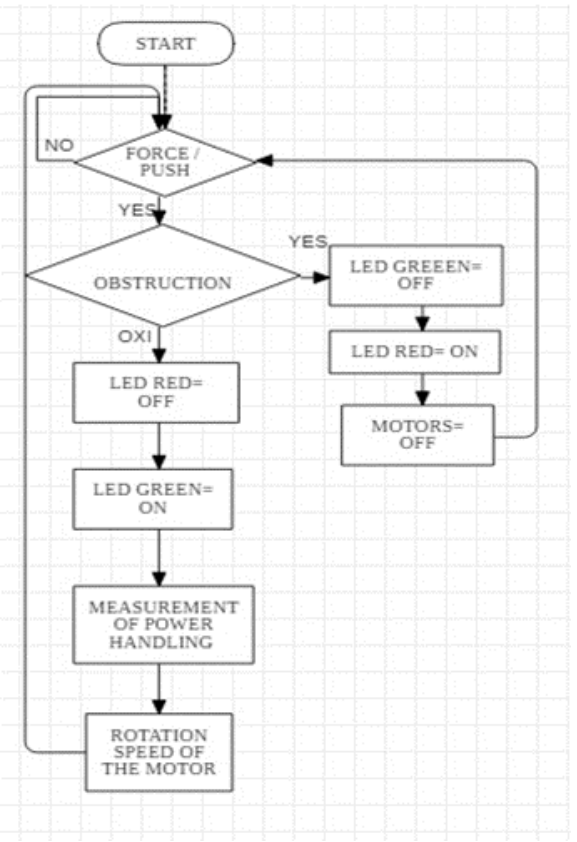

Fig 1: Flow diagram depicting the operation of the automated system.

\section{IMPLEMENTANTION}

\subsection{Data-Calculations}

Initially, the weight of the trolley (tare weight) is measured using electronic scales. On the traction is then measured in order to capture the force required to start the roller and to roll it. $[2,9,10,11]$

Weight of empty trolley (tare weight) 15,50 Kp.

Empty carts are filled with water, which is a heavy weight that is easily taken to observe the variation in traction and Inertia traction.

It is stated that the Elbow is equal to the force F, so it follows:

1) Empty the trolley was measured at $\mathrm{F}=0,300 \mathrm{Kp}$

2) With Six-pack of 1,5 liter water bottles at $F=0,480$ $\mathrm{Kp}$

3) With two Six-pack of 1.5 liter water bottles at $F=$ $0,600 \mathrm{Kp}$

4) At start with a Six-pack of 1,5 liter water bottles at $F=$ $1,300 \mathrm{Kp}$

Below, we present the basic formulas by which these desired sizes (torque and speed) are calculated in order to select the right motor and the appropriate wheel to allow the trolley to roll with minimal thrust. Two motors and two wheels are used on the rear of the trolley.

Torque calculation is done through Equation 1:

$\mathrm{F}=\mathrm{T} / \mathrm{r} \Rightarrow \mathrm{T}=\mathrm{F} \times \mathrm{r}$, the units should be $\mathrm{Nm}=(\mathrm{N}) \times(\mathrm{m})$ (Eq. 1)

Where: $\mathrm{r}=$ circle radius (wheel radius) in $\mathrm{m}$

$\mathrm{T}=$ torque the force to rotate $\mathrm{N}$

$\mathrm{F}=$ the total force needed to move the $\mathrm{N}$

Applies $1 \mathrm{Kp}=9,86 \mathrm{~N}$

The calculation of the motor speed and rotation speed of the motor and thus of the wheel is carried out by means of Equation 2:

$\mathrm{V}=\omega \mathrm{xr}=2 \pi \mathrm{nxr}=>\mathrm{n}=\mathrm{V} / 2 \pi \mathrm{r}$, at $\mathrm{rps}=((\mathrm{m} / \mathrm{sec})) / \mathrm{m} \quad$ (Eq. 2)

Where:

$\mathrm{n}=$ rotational speed in rps

$\mathrm{r}=$ radius in $\mathrm{m}$

$\pi=3,14$

$\mathrm{V}=$ motion speed in $\mathrm{m} / \mathrm{sec}$

To convert rps to rpm is multiplied by 60 .

Power calculation is done through Equation 3:

$\mathrm{P}=2 \pi \mathrm{nxT}$, at $\mathrm{w}=(\mathrm{rps}) \times(\mathrm{Nm})($ Eq. 3$)$

Where:

$\mathrm{P}=$ power in $\mathrm{w}$

$\pi=3,14$

$\mathrm{n}=$ turns in $\mathrm{rpm}$

$\mathrm{T}=$ torque in $\mathrm{Nm}$

An exploration is then made to select the most suitable materials for construction by calculating the torque of the motor during pulling and 2) the speed of the trolley according to its weight, using Values 1 and 2.[1,3]

\subsubsection{Motor torque calculation}

Table 1 presents the results of the torque calculations in relation to the various wheels and the various weights placed on the trolley in order to select the corresponding wheel in relation to the weight of the trolley (yellow and underlined rows).

From Table 1 it is observed that the larger the wheel, the greater the torque required on the motor. In addition, for the wheels of all sizes it is noticeable that the torque at the starting point requires a sufficiently high torque $(66,75 \mathrm{~N})$ as opposed to the traction in motion where the torque required is 2,5 times less $(24,65 \mathrm{~N})$. Therefore, the starting pull as the worst case should be taken into account as a selection factor so that the trolley starts its movement. Thus it is selected as an intermediate torque and wheel, the radius of $4,9^{\prime \prime}$ and the 50 $\mathrm{kp}$ torque corresponding to a standard $24 \mathrm{kpcm}$ motor. The rationale behind Table 1 should be added. 
Table 1. Momentum calculations for different wheel and weight sizes

\begin{tabular}{|c|c|c|c|c|c|}
\hline 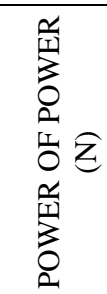 & 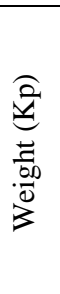 & 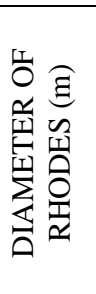 & 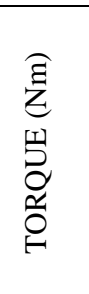 & 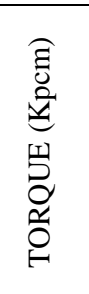 & 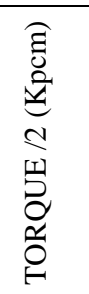 \\
\hline 30 & 60 & 0,1 & 1,5 & 15,29 & 7,64 \\
\hline 30 & 60 & 0,124 & 1,86 & 18,96 & 9,48 \\
\hline 30 & 60 & 0,152 & 2,25 & 22,94 & 11,74 \\
\hline 30 & 60 & 0,2 & 3 & 30,59 & 15,29 \\
\hline 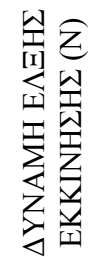 & 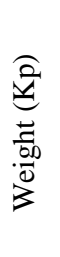 & 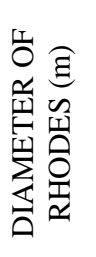 & 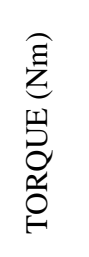 & 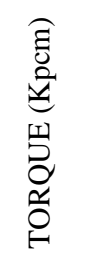 & 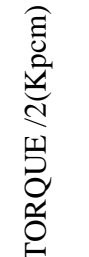 \\
\hline 80,11 & 60 & 0,1 & 4 & 40 & 20,39 \\
\hline 80,11 & 60 & 0,124 & 4,96 & 50,57 & 25,28 \\
\hline 80,11 & 60 & 0,152 & 6 & 61,18 & 30,59 \\
\hline 80,11 & 60 & 0,2 & 8,011 & 81,68 & 40,84 \\
\hline 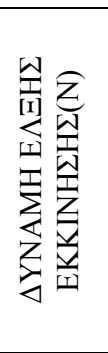 & 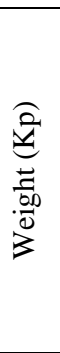 & 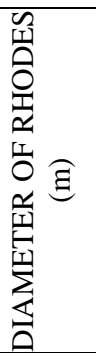 & 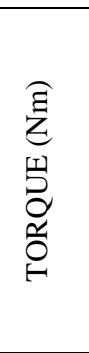 & 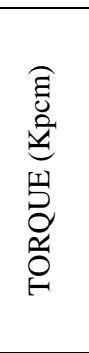 & 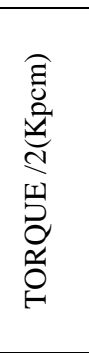 \\
\hline$\underline{66,75}$ & $\underline{\mathbf{5 0}}$ & $\underline{\mathbf{0}, 124}$ & $\underline{4,13}$ & $\underline{42,11}$ & $\underline{21,05}$ \\
\hline 66,75 & 50 & 0,152 & 5 & 50,98 & 25,49 \\
\hline 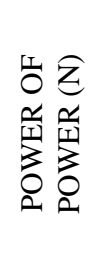 & 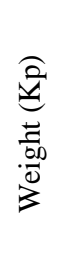 & 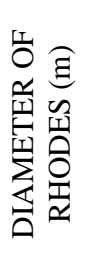 & 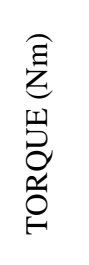 & 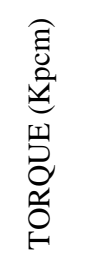 & 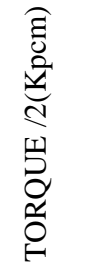 \\
\hline$\underline{24,65}$ & $\underline{50}$ & $\underline{0,124}$ & $\underline{1,52}$ & $\underline{15,49}$ & $\underline{7,74}$ \\
\hline
\end{tabular}

Indicatively, calculations for determining the torque for a wheel with a radius of 4,9 "are shown.

For a 4,9 "wheel and a weight of 50K the traction at the start (the worst) will be calculated through Equation 1 as shown in Table 2.

Initially, the inch is converted into meters: $4,9 "=0,124 \mathrm{~m}$

And so the radius of the wheel will be $=0,124 \mathrm{~m} / 2=0,062$ $\mathrm{m}$

\section{Table 2. Calculation of traction force at start}

\begin{tabular}{|c|c|c|}
\hline \multirow{2}{*}{} & \multicolumn{2}{|c|}{ Starting force at start } \\
\cline { 2 - 3 } & $(\mathrm{Kp})$ & $(\mathrm{N})$ \\
\hline $\begin{array}{c}\text { 1 Six-pack of 1.5 liter } \\
\text { water weighs 9.6Kp }\end{array}$ & 1,300 & 12,82 \\
\hline $\begin{array}{c}\text { for a total product } \\
\text { weight of 50Kp }\end{array}$ & 6,77 & 66,75 \\
\hline
\end{tabular}

For $66,75 \mathrm{~N}$ the torque $(\mathrm{T})$ for traction at start will be through Equation 1:

$\mathrm{T}=66,75 \times 0,062=4,13 \mathrm{Nm}=>$ Converting to $42,11 \mathrm{Kpcm} /$ $2=21,05 \mathrm{Kpcm}$ results in torque on each wheel and therefore on each motor.

Unit conversion: $\mathrm{Nm}$ to $\mathrm{Kpcm}$,

Applies $1 \mathrm{Nm}=0,101 \mathrm{Kpm} 4,13 \mathrm{Nm}=0,421 \mathrm{Kpm} * 100 \mathrm{~cm}=$ $42,1 \mathrm{Kpcm}$.

For a 4,9" wheel and a $50 \mathrm{Kp}$ weight, traction in motion is through Equation 1, as shown in Table 3.

Table 3. Calculation of pull force in motion

\begin{tabular}{|c|c|c|}
\hline \multirow{2}{*}{} & \multicolumn{2}{|c|}{ Starting force at start } \\
\cline { 2 - 3 } & $(\mathrm{Kp})$ & $(\mathrm{N})$ \\
\hline $\begin{array}{c}\text { 1 Six-pack of } \\
1.5 \text { liter water } \\
\text { weighs 9.6Kp }\end{array}$ & 0,480 & 4,73 \\
\hline $\begin{array}{c}\text { for a total } \\
\text { product weight } \\
\text { of 50Kp }\end{array}$ & 2,5 & 24,65 \\
\hline
\end{tabular}

The torque for 24,65 $\mathrm{N}$ will be through Equation 1:

$\mathrm{T}=24,65 \times 0,062=1,52 \mathrm{Nm}=>$ Converting to $15,49 \mathrm{Kpcm} /$ $2=7,74 \mathrm{Kpcm}$ results in torque on each wheel and therefore on each motor.

- For a 4,9 " wheel and a weight of $60 \mathrm{Kp}$ the pull at start (worse) will be:

Table 4. Calculation of traction force at start

\begin{tabular}{|c|c|c|}
\hline \multirow{2}{*}{} & \multicolumn{2}{|c|}{ Starting force at start } \\
\cline { 2 - 3 } & $(\mathrm{Kp})$ & $(\mathrm{N})$ \\
\hline $\begin{array}{c}\text { 1 Six-pack of 1.5 liter } \\
\text { water weighs 9.6Kp }\end{array}$ & 1,300 & 12,82 \\
\hline $\begin{array}{c}\text { for a total product } \\
\text { weight of 60Kp }\end{array}$ & 8,125 & 80,11 \\
\hline
\end{tabular}

The torque for $80,11 \mathrm{~N}$ will be through equation 1 :

$\mathrm{T}=80,11 \times 0,062=4,96 \mathrm{Nm}=>$ Converting to $50,57 \mathrm{Kpcm} /$ $2=25,28 \mathrm{Kpcm}$

\subsubsection{Speed and speed calculation of $H / K$}

In order for the trolley to follow the walking of the man, the desired speed that the trolley should develop is on average $\mathrm{V}$ 
$=3 \mathrm{Km} / \mathrm{h}=0,83 \mathrm{~m} / \mathrm{s}$.

Using Equation 1, the motor will achieve this speed should develop the following turns:

equation 1: $\mathrm{n}=\mathrm{V} / 2 \pi \mathrm{r}=0,83 / 2 \times 3,14 \times 0,062=2,133 \quad \mathrm{rps}$ $=>2,133 \times 60 \mathrm{rpm}=127,98 \mathrm{rpm}$

In the present study, the engine with the specified specifications was not selected due to the purchase cost. Alternatively, an exploration is made to select another motor which, when pulled on the trolley, will approach the ideal speed conditions and at the same time be economical. Therefore, it is selected as an intermediate torque and wheel, the radius of 4.9 "and the $50 \mathrm{kp}$ torque corresponding to a standard $24 \mathrm{kpcm}$ motor.

Table 5. Speed variations of trolley e trand engine speeds according to the different wheel diameters.

\begin{tabular}{|c|c|c|}
\hline $\begin{array}{c}\text { DIAMETER } \\
\text { OF ROD (m) }\end{array}$ & $\begin{array}{c}\text { ROTS (rpm) } \\
\text { FOR 3 (Km } \\
/ \mathrm{h})\end{array}$ & $\begin{array}{c}\text { FOR } \\
\text { FLIGHTS 30 } \\
\text { (rpm) SPEED } \\
(\mathrm{Km} / \mathrm{h})\end{array}$ \\
\hline 0,1 & 158,58 & 0,565 \\
\hline$\underline{\mathbf{0 , 1 2 4}}$ & $\underline{\mathbf{1 2 7 , 9 8}}$ & $\underline{\mathbf{0 , 6 9 8}}$ \\
\hline 0,152 & 113,4 & 0,846 \\
\hline 0,2 & 79,2 & 1,13 \\
\hline
\end{tabular}

From the above results and the choice of wheel 4,9" and the standard $24 \mathrm{kpcm}$ torque, the speed given by the manufacturer is $30 \mathrm{rpm}$. Then the speed is calculated with given speeds. Therefore, in Table 5 for the given speeds, $30 \mathrm{rpm}$, the speed in $\mathrm{Km} / \mathrm{h}$ is calculated (Column 3, in this case) and for the given speed $\mathrm{V}=3 \mathrm{Km} / \mathrm{h}$, the engine speed is calculated in rpm (Column 2, ideal case).

Indicatively, the speed calculations for the wheel finally selected with a diameter of $0,124 \mathrm{~m}\left(4,9^{\prime \prime}\right)$ and a speed of $0,698 \mathrm{Km} / \mathrm{h}$ (yellow and underlined line of the table) are shown.

\subsubsection{Calculation of the axle in complex stress}

The axles of the trolley are stressed both in torsion and bending. In torsion, the shaft rotates with a torque (force) resisting its movement and bending the weight it receives with the products loaded. Thus, the calculation of the magnitude of the spindle is made by calculating the equivalent torque $\mathrm{Mv}$ (Equation 4) and then the spindle d (Equation 5). Two cases where the cart is loaded with different weights.[1,3]

Product weight $50 \mathrm{Kp}$ :

$\mathrm{M} v=\sqrt{ }\left(\llbracket \mathrm{M} \_\mathrm{b} \rrbracket \wedge 2+0,75 \times\left(\mathrm{a} \_0 \times \mathrm{T}\right)^{\wedge} 2\right)(\mathrm{Eq} .4)$

Explain the parameters / variables of the equation

Where:

$\mathrm{M} v=$ equivalent torque in $\mathrm{N} \mathrm{mm}$

$\mathrm{M} \_\mathrm{b}=$ bending moment in dangerous cross-section in $\mathrm{Nm}$

M_b = FxL, force at the end of the wheel at this distance (from the base with the bearings) in $\mathrm{Nm}$.

$\mathrm{T}=$ torque transmitted on the shaft in $\mathrm{Nm}$.
Convert from $\mathrm{Nm}$ to $\mathrm{Nmm}$

a_ $(0=)$ strain ratio. The values are derived from the following (Table 6). The case $\alpha_{-} 0=0.4$ is chosen because it changes the weight but the torque in the motor operation is constant.

Table 6. Select $\alpha_{0}$ as appropriate

\begin{tabular}{|c|c|}
\hline$\alpha_{0}=1$ & $\begin{array}{c}\text { Bending and torsional } \\
\text { stresses belong to the } \\
\text { same charging case and } \\
\text { both have a reversed or } \\
\text { recurrent load }\end{array}$ \\
\hline$\alpha_{0}=0,7$ & $\begin{array}{c}\text { Reversible bending and } \\
\text { repeated torsion }\end{array}$ \\
\hline$\alpha_{0}=0,4$ & $\begin{array}{c}\text { Reversible bending and } \\
\text { static torsion }\end{array}$ \\
\hline
\end{tabular}

A force analysis (Figure 2) is performed on the wheel to determine $\mathrm{F}_{\mathrm{o} \lambda}$, ie the force the wheel receives from the products it has on the trolley and the pulling force (torque) to move.
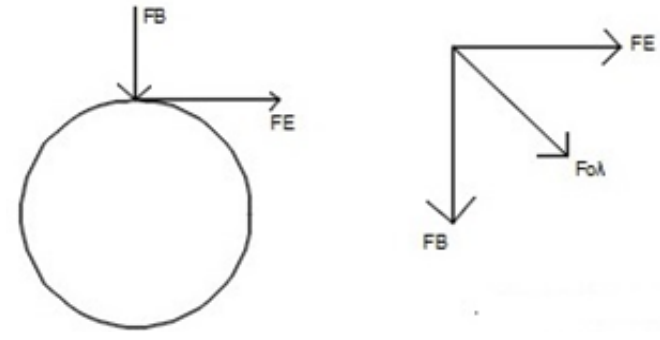

Fig 2: Flow diagram depicting the operation of the automated system.

$$
M_{b}=F_{o \lambda} \mathrm{xL}
$$

- $15,50 \mathrm{Kp}$ (empty cart) $+50 \mathrm{Kp}$ (products) $=65,50 \mathrm{Kp}$, therefore 16,37 Kp ๆ́ 161,41 N per wheel (4 wheels).

Put the force on the weight each wheel receives: $\boldsymbol{F}_{\boldsymbol{B}}=\mathbf{1 6 1 , 4 1} \mathrm{N}$

The traction force at start is calculated based on the weight of $50 \mathrm{Kp}$ on the trolley and the value of $6,77 \mathrm{Kp}$ or $66,75 \mathrm{~N}$ (Eq $1)$ :

\section{$F_{E}=66,75 \mathrm{~N}$}

Therefore, $F_{o \lambda}=\sqrt{{F_{B}{ }^{2}+{F_{E}}^{2}}^{2}}=\sqrt{161,4^{2}+66,75^{2}}=174,658$

$F_{o \lambda}=174,66 \mathrm{~N}$

The distance between the wheel and the base with the bearings, that is, the axis at that point has a length:

\section{$\mathbf{L}=\mathbf{0 , 0 3 6} \mathrm{m}$}

Therefore,

$M_{b}=F_{o \lambda} \times L=174,66 \times 0,036=>M_{b}=\mathbf{6 , 2 8} \mathbf{~ N m}$

Torque has a value $\mathrm{T}=F_{E} \mathrm{xr}=66,75 \times 0,062=4,13 \mathrm{Nm}$

Where $\mathrm{r}=0,062$ radius in $\mathrm{m}$

This is the total torque that the two wheels have with the motors together and dividing by 2 the torque for each wheel:

\section{$\mathrm{T}=\mathbf{2 , 1 7} \mathrm{Nm}$}

$\boldsymbol{a}_{\mathbf{0}}=\mathbf{0 , 4}$ from (Table 6 ) 
Thus, with substitution it follows:

Mv

$$
=\sqrt{M_{b}{ }^{2}+0,75 \times\left(a_{0} \times T\right)^{2}}
$$

$\sqrt{6.28^{2}+0,75 \times(0.4 \times 2.17)^{2}}=>$

\section{$\mathrm{M} v=6,325 \mathrm{Nm} \eta \dot{M} \mathbf{M v}=\mathbf{6 3 2 5} \mathbf{~ N m m}$}

The calculation of the spindle is accomplished by Equation 5:

$\mathrm{d} \approx \sqrt[3]{\frac{\mathrm{M} v}{0,1 \times \sigma_{\mathrm{b \varepsilon \pi}}}}$

$\mathrm{Mv}=$ equivalent torque in $\mathrm{Nm}$

$\sigma_{b \varepsilon \pi}=64 \mathrm{~N} / \mathrm{mm}^{2}$ (according to its material, Ck45 steel, made of the shaft)

Therefore,

$d=\sqrt[3]{\frac{6325}{0,1 \times 64}}=d=9,96 \mathbf{m m}$

Hence, the axis should be greater than $d=9.96 \mathrm{~mm}$

Table 7.Complex Scoreboard for Axis Selection.

\begin{tabular}{|c|c|c|}
\hline $\begin{array}{c}\text { TOTAL } \\
\text { WEIGHT }(\mathrm{Kp})\end{array}$ & $\begin{array}{c}\text { PRODUCT } \\
\text { WEIGHT } \\
(\mathrm{Kp})\end{array}$ & AXLE (mm) \\
\hline 65,50 & 50 & 9,96 \\
\hline 45,50 & 30 & 8,75 \\
\hline
\end{tabular}

\subsection{Materials and system operation}

The supermarket trolley, which will require the minimum physical thrust for movement, has been used with the following wiring. Initially, two loadcells are placed on the right and left of the handle and receive the force exerted by the man on the handle by distortion of the resistances that include. On then, the two power cells connected to the HX711 dynamocell signal amplifiers, respectively, carry the signal to Arduino. Arduino handles the command received by the amplifier in communication with the distance sensor (HCSR04), which detects the presence of a bar in front of the trolley in order to allow (Green) the movement of the trolley (Led red). If allowed, the Arduino motion command is transferred to the L298N integrated circuit board, which sends a signal to both motors respectively mounted on the two rear wheels. If the signal is + (pushing the trolley by the man) the motor and therefore the wheels turn clockwise and the trolley moves forward while when it is - (pulling the trolley back from the man) the motor and the wheels are turning left rotate and the trolley will move backwards.

All components communicated with each other via the Arduino microcontroller, which allows the simplification of complex procedures. In particular, programming code was developed in Arduino, with specific commands for each component to interact with the Arduino components. Arduino processes the communication data in order to execute the commands for the functions of the above paragraph.

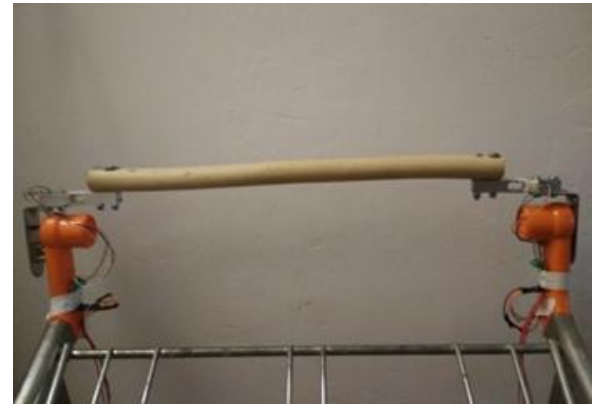

Fig 3: The trolley handle with Load cell mounted

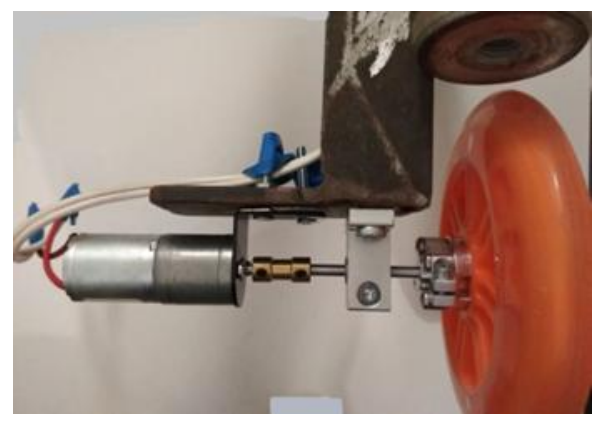

Fig 4: Wheel-motor assembly.

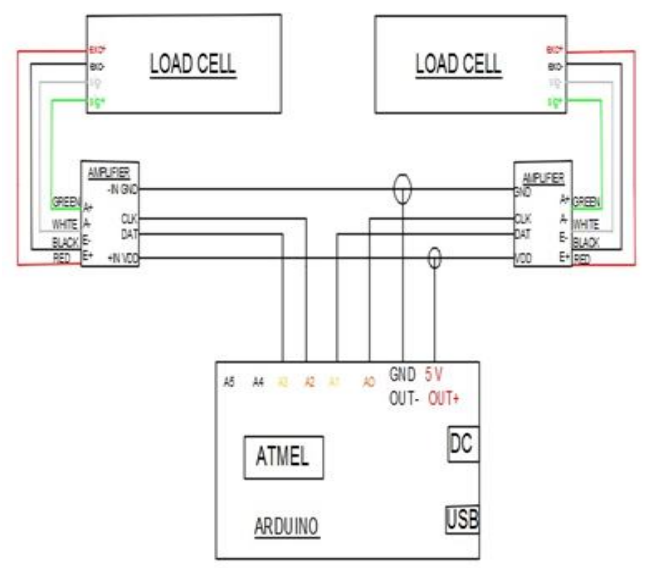

Fig 5: Load connection - HX711 - Arduino.

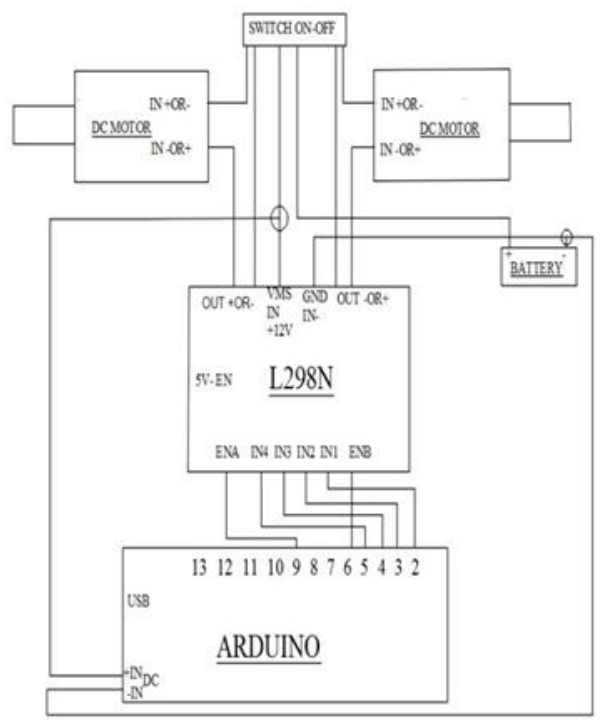

Fig 6: Connector- L298N-battery-Arduino. 


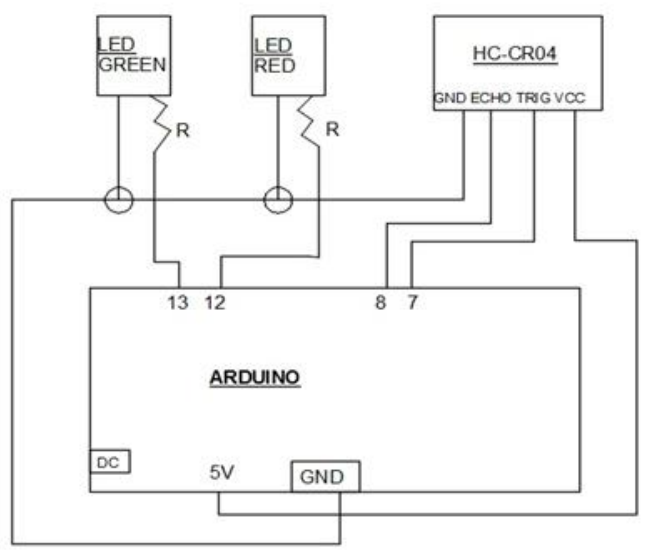

Fig 7: HC-SR04-Led-Arduino connection.

\subsection{Energy consumption}

Note that all this is powered by a $12 \mathrm{~V}$ battery that is directly connected to the L298N and Arduino while all the rest are fed through them. The total consumption of all components is 1.15 Amp.

\section{RESULTS}

From the investigation conducted on the motor specifications required to build the supermarket trolley, the design motor of this paper was selected. It is noted that this investigation was carried out in relation to the cost of the motor and eventually led to the choice of the motor with speed $\mathrm{n}=30 \mathrm{rpm}$ and torque $\mathrm{T}=24 \mathrm{kpcm}$.

The choice of engine torque was made according to the specifications while the choice of engine speed did not follow the specifications due to the trolley movement at a speed of $0,698 \mathrm{Km} / \mathrm{h}$, less than $3 \mathrm{~km} / \mathrm{h}$, a speed that is related to the average human motion. Though the drive speed was lower than expected, it was achieved using this motor moving the trolley weighing $50 \mathrm{kp}$.

It was observed that with the materials used, namely HX711, loadcell $10 \mathrm{Kg}$ there was a delay of a few seconds to stop in some movements which may be due to either the HL711 microcontroller being too slow or the loadcell not being be very sensitive. great pushing force. Instead, the DC motors, without the stop command passing through the two above, showed an immediate response to their stopping. At the beginning there was no error with them.

The design and manufacture of the trolley, which requires the minimum physical strength to move, is an innovative approach to facilitating consumers in Greece.

Figures 8,9 show the power the consumer exerts to move the trolley without using the motor and using the motor. Instead, it exerts less force to move until it reaches the default force on the load cells, for example, the 0,300 $\mathrm{Kp}$ and 0,600 Kp. Finally we notice that the force to start moving (powerpulling) is quite high in relation to being in motion.

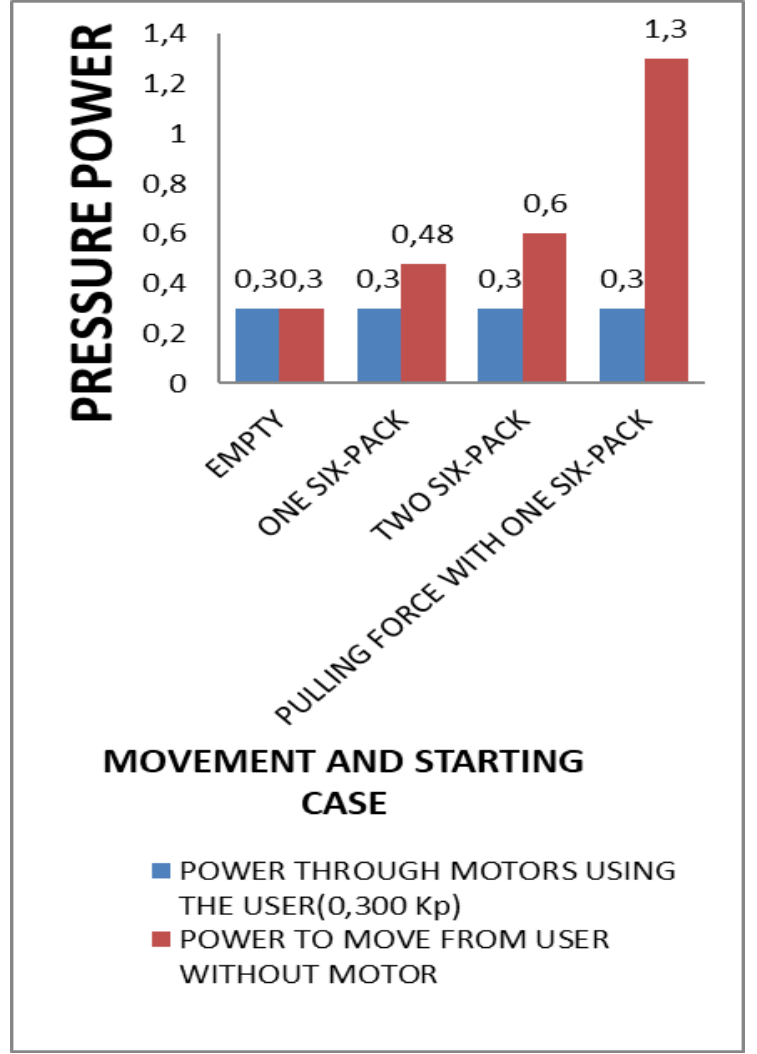

Fig 8: The power of the consumer to move the trolley by using the motor in relation to the preselected force of $0,300 \mathrm{Kp}$.

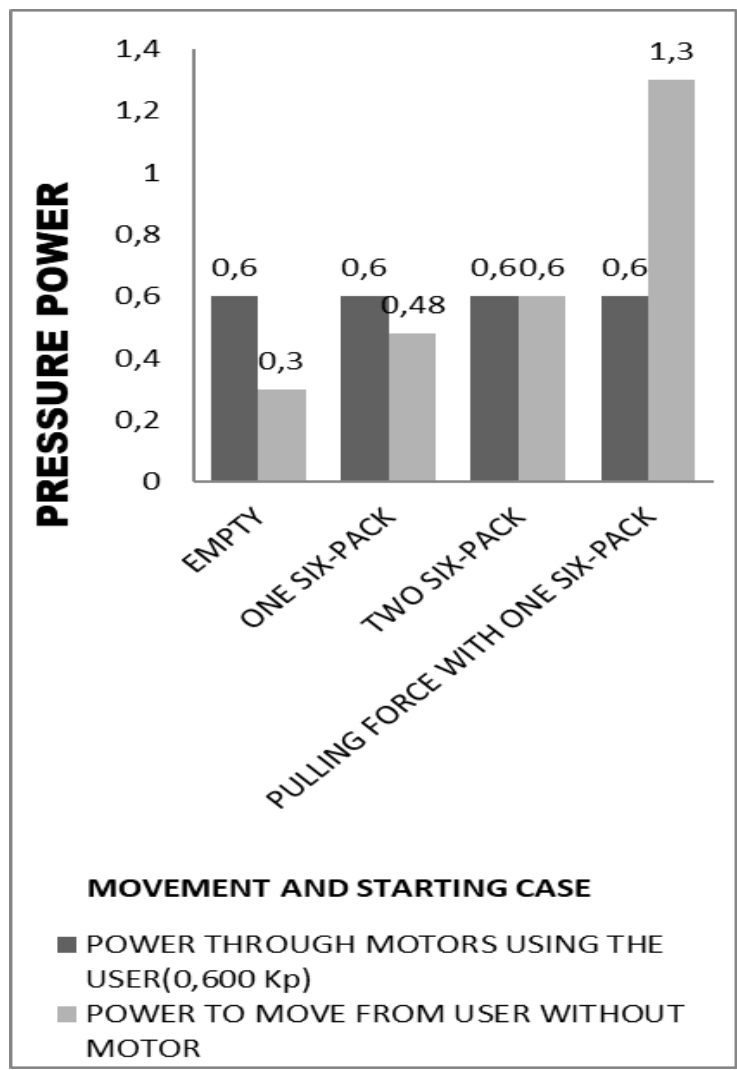

Fig 9: The power of the consumer to move the trolley using the motor in relation to the preset power of 0,600 Kp. 


\section{CONCLUSIONS}

In the present study, the most economical way was to develop an automation system based on its possible application for the benefit of society, facilitating the consumer in his everyday life and clearly vulnerable social groups. The supermarket cart designed and built moves with the minimum human body strength with a $50 \mathrm{kp}$ load bearing capacity.

Innovation of the present work is the direct response of the loadcell system, placed in the trolley, to the push of the man on the handle of the trolley, which is first proposed in Greece.

The programming code has been developed successfully, resulting in the proper communication of all parts with Arduino, which gives the ultimate command of the motors for the trolley movement. The choice of these motors has led to greater autonomy with respect to the most powerful motors because of the higher needs of the latter in ampere (higher consumption).

This automation system achieves precision movement due to the presence of the motor in conjunction with the distance sensor, which detects obstacles in front and allows or prevents the trolley from moving. Therefore, the trolley becomes safe when passing through the supermarket corridors, avoiding collision accidents either with people or with the equipment and the supermarket products.

\section{REFERENCES}

[1] Ioannis K. Stergiou, Konstantinos I. Stergiou, "Machine Elements 1", Synchronous Publishing, Athens 2003.

[2] David M. AuslanderCarlJ. Kempf, "Mechatronics: Adaptive Computer Systems", University Press, Athens, 1998.
[3] Hamrock Bernard J., Schmid Steven R., Jacobson Bo O. "Fundamentals of machine elements", second edition, international edition 2006

[4] Yen Leng Ng, Cheng Siong Lim, Kumeresan A. Danapalasingam, Michael Loong Peng Tan, Chee Wei Tan, " Automatic Human Guided Shopping Trolley with Smart Shopping System", Faculty of Electrical Engineering, UniversitiTeknologi Malaysia, 81310 UTM Johor Bahru Johor, Malaysia,2015.

[5] SnehaS.Nik ,Saily A. Prabhudessai, Pooja N. Velip, Ashwini H. Joshi,MelbaD'souza, "Multi-Featured Shopping Trolley with Billing System", IJIRST,Volume 2, March 2016.

[6] Harpreet Singh Bedi, Nikhil Goyal, Sunil Kumar and Avinash Gupta, 'Smart Trolley using Smart Phone and Arduino", Department of Electronics and Electrical Engineering, Lovely Professional University, Phagwara, Punjab, India,2017.

[7] You-Chiun Wang, Chang-Chen Yang, “ Intelligent Shopping Trolley (IST) System by WSN to Support Hypermarket IoT Service", National Sun YatsenUniversityKaohsiung, Taiwan, R.O.C.

[8] J. H. Swinny, "motorized steerable nestable service cart", United States Patents3,190,386 ,June,1965.

[9] Poulakis E., "Planning with the Microducker Arduino", Heraklion, 2015.

[10] Kalofolias D., "The programming of the atmga328 microcontroller using the Arduino platform", Giola 1st Edition, 2017 